tion states by age groups in the years 1900 and 1910 shows that the percentage of persons living in each age period did not vary by 1 per cent. in the ten years. The percentage of population included in the ages 0 to 40 years in 1900 was 72.80 and in $1910,72.58$, while the percentage of population included in the ages after 40 years in 1900 was 27.20 , and in 1910, 27.42, differences so slight that they are negligible. More convincing is a comparison of the specific mortality rates. These rates are computed on the cancer deaths in certain groups of population, and no matter what changes are taking place in the composition of a population the only factor which could change the mortality rates within these groups would be an actual increase or decrease in the number of deaths per one hundred thousand in any particular group. We have seen in Tables 3 and 4 there was a marked increase which is specific for each age period, and which must be in itself genuine.

If we cannot account for the increase in the cancer mortality by better diagnosis or by changes in the composition of the population I submit that for the past decade the cancer rates in the registration area show a true increase.

16 West Saratoga Street.

\section{HOSPITAL INTERNSHIPS IN OPHTHALMOLOGY *}

\author{
E. C. ELLETT, B.A., M.D. \\ MEMPHIS, TENN.
}

There are çertain matters of interest to which your attention should be called. The first is in regard to the comparative shortness of the program. We were limited this year to fifteen papers, on account of the fact that the second day of the meeting is to be given up to exercises to commemorate the completion of the Panama Canal. In view of the important part that our profession has played in making possible the achievement of this great work, it is fitting that we turn aside for a moment from the main object of our coming together, and pay tribute to those workers whose discoveries and attainments have erected to their memories a "monument more lasting than brass."

We have further cause for a season of congratulation in that we are devoting ourselves to the celebration of a great commercial and engineering accomplishment, a work of peace, at a time when the older nations of the earth are wrapped in a terrible, destructive and desolating struggle; and in the enjoyment of the blessings of conditions that permit the unruffled pursuit of our usual work, we should not fail to both feel and express our sympathy for those, bound to t1s by the ties of a common task, whose lot is less fortunate, whose ways are less tranquil and whose labors are so rudely interrupted.

It has been the custom for many years for the section to invite a distinguished visitor from some other country to be a guest at the meeting; but after due consideration it was decided not to extend such an invitation this year. Disturbed conditions in Europe made it very doubtful if any of those whom we specially desired would have found it possible to come, and the shortness of the program already referred to made it

* Chairman's address, read before the Section on Ophthalmology at the Sixty-Sixth Annual Session of the American Medical Association, Sin Francisco, June, 1915. seem advisable to give the time to our own members as a matter of choice and in justice to those who have brought the section to its present efficiency. Before the weight of these two conditions was fully realized, a sentiment was gaining ground to the effect that occasional, instead of regular, invitations to foreigners to participate in our meetings would be a more dignified attitude for us to adopt, and would at the same time make the recipient feel that he was the more complimented. In view of these facts, the officers of the section feel that they do not need to offer any apology for the omission of this feature.

The policy of the program has been, as in previous years, to encourage as much as possible those men who have not heretofore contributed to our proceedings; but you will find on the list some of those well-known names, without which a meeting of this section could hardly be successfully conducted, men to whom it is our pleasure to listen again and again. "Age cannot wither" them, "nor custom stale" their "infinite variety"; and may the day be far distant when our deliberations will lose the leaven of their presence.

Let me remind you, as my immediate predecessors have done, that the admirable features of the program are due to the energetic and well-directed efforts of our secretary, whose labors are the keystone of the arch, and without which our structure would fall to the ground. Nothing that I could say would be more than should be said in acknowledgment and appreciation of his more than efficient work, and those particulars wherein the program falls short of your expectations mark the occasions when an officious chairman or executive committee has interfered with his plans.

From appropriate committees a number of interesting subjects will be presented for your consideration, and among the most important is that of the Committee on Education in Ophthalmology. Their report is printed and will be distributed in time for it to be read by each of you before it is brought up for discussion and action. This committee, as you will see, met similar committees from the American Ophthalmological Society and the American Academy of Ophthalmology and Oto-Laryngology in Boston in October, and will present for your approval a plan whereby a board of nine would be appointed from these three organizations to pass on the qualifications of those desiring to appear as specialists in ophthalmology. While such a board will have no legal standing, its seal of approval can easily become the hall mark of genuine merit, and properly managed and supported by the organizations which create it, such a board could accomplish a great deal. Expressions from many quarters justify the expectation that this suggestion will be favorably received, and since this section has never been remiss in identifying itself with those things which stand for the advancement of ophthalmology, it can be expected to consider carefully their proposal, and approve it if it, seems to promise what its sponsors believe it will do.

Another communication of much interest is that from the Committee on the Conservation of Vision. Although a child of this section, this committee was a youngster of such promise that it was weaned away from its real parent and adopted by the Council on Health and Public Instruction. We still retain an interest in its purposes and welfare, and are glad to know, from Dr. Allport's report, of the very excellent work which is being done. The need of some central 
organization with sufficient funds and adequate machinery for carrying on this work is being felt by all who have concerned themselves in it. Dr. Allport has given much time and labor to this matter, as any member of his committee can testify; but it is not good that the welfare of so great a cause should depend on the self-sacrificing efforts of any one man. It is hoped that all the interests looking to the conservation of vision will be federated and the work carried on from an adequate center.

Thanks to the activity and energy of the members of the committee, the Knapp fund continues to serve the usual purposes for which it was founded.

The fund furnishes the Knapp Medal for meritorious work presented to this section. The committee on award is of the opinion that no contribution made to the last meeting was sufficiently noteworthy to justify conferring the medal this year. Certainly the fund deserves the cordial support of all those interested in the progress of ophthalmology, and I especially request you all to support it. Subscriptions in sums of less than $\$ 10$ will be gladly received, but they do not entitle the subscriber to the two volumes mentioned.

It is the custom for the chairman of this section to make some reference in his address to such point or points of interest to the Section on Ophthalmology as he thinks should have special attention or investigation. In accordance with that custom, it is my desire to invite your further consideration of certain aspects of the question which have been so to the fore in recent years, the preparation of the ophthalmologist for his his work. A phase of this subject which has not yet been touched on very fully is that of the available facilities for hospital work. Closely related to this are the plans which have been put into force in two of our leading state universities. One which was explained to you at length by my predecessor has had further trial during the past year at the University of Minnesota, and has given great satisfaction. Briefly, it consists in the employment of a number of men for a period of three years, at an increasing salary, who assist in the clinical work and in the instruction of the undergraduate and graduate students. These men are designated as "fellows," and the scheme contemplates the ultimate employment of six. The development of this plan was brought out in a paper before the Conference on Medical Education in Chicago in February. A somewhat similar plan is in vogue at the University of Michigan, where a man serves the department for three years as intern, assistant and instructor, respectively, one year each, at a salary which increases each year. The duties of the intern require no special elucidation. The second year is spent as assistant to the head of the department, with full charge of the operating room and morning treatments of all outpatients. In the third year he gives instruction in refraction, does refraction, and has charge of the laboratory in the mornings.

This scheme has suggested the idea that the very interesting work on the classification of hospitals by the Council on Medical Education, and the parallel work about to be undertaken by the American College of Surgeons, might be advantageously supplemented at this time by collecting information relative to the work offered by various special hospitals in this country in the shape of internships. A questionnaire was therefore formulated and sent to all the special hospitals listed in the American Medical Directory, and I wish to present to you the data gathered from a perusal of the replies. That this information is incomplete is true, but every one who has attempted a collective investigation will sympathize with the fruitless efforts that were made to secure responses from all the hospitals. Some institutions were inadvertently omitted, but the result is nevertheless of some worth.

The value of an internship is particularly great in postoperative work, but almost equally great in certain severe inflammatory and traumatic conditions. The whole question is summarized, and much more is suggested, by considering the case of those men who have had.good "courses" in ophthalmology, with cadaver and clinical work, and who can perform a creditable operation for cataract, for instance, but who cannot tell the next day whether or not the eye is pursuing a normal and satisfactory postoperative course.

Answers were obtained by some means from twenty. five institutions. Many of these are eye, ear, nose and throat hospitals; but as far as possible to ascertain them, the facts set forth apply to the eye service alone. It was impossible to arrive, by any reasonable effort, at the facts concerning the special departments of general hospitals, but it must not be forgotten that in many of these an excellent service in ophthalmology can be obtained, and this is especially valuable where an outpatient department is also accessible to the interns. In such a case, the tour of duty for the intern should be simultaneous in the wards and outpatient department, since many of the patients are never house patients, and a service limited to the house would be inadequate. It would afford no opportunities for refraction, perimetry, muscle work, etc., and very limited ones for ophthalmoscopy.

Comments on the subject can be best made in a general way, because the information was not always exact. Previous general hospital experience is always desirable, but seldom required of an applicant. Since the supply of positions does not equal the demand, hospitals can fix rather high requirements, and certainly previous hospital experience, or a satisfactory equivalent in general practice, would be very desirable not only to the institution, but also to the future ophthalmologist, and should be a necessary condition for the applicant.

An outpatient department is maintained by all the hospitals answering this inquiry, but indefinite information was given in regard to interns' duties in that department. Unless the arrangement is to appoint the intern from the clinical assistants, or from externs, the interns should serve a definite tour of duty in the outpatient department, because the work in the house alone does not give sufficient experience with the various forms of functional examination and with the use of the ophthalmometer, ophthalmoscope, perimeter, and tropometer, with which one must be familiar. Refraction, which constitutes such a large and important part of the daily work of the ophthalmologist, can be learned only by practice, and the opportunity for this is found only among the outpatients. The same can be said of many of the minor ailments and milder inflammatory diseases, which constitute a much larger part of one's work, especially in the beginning, than serious maladies and capital operations.

In reading over the replies to the circular letter, one is impressed with the fact that a hospital intern is no longer at school. Little is demanded of him beyond a certain amount of routine work. He does some 
history taking, which varies greatly in quantity and quality in different places, and renders a certain assistance in the care of patients, operating room duties, etc. He has abundant opportunities, but there is no one whose duty it is to see that he profits by them. In the larger institutions with a graded house staff this is not the case, and the junior is not only given a certain amount of instruction by the senior, but is required to perform certain duties. This is very desirable, and in proportion as this system does not exist, the present plan seems to fall short of accomplishing the best results. As was pointed out in the report of the Committee on Hospital Efficiency of the Philadelphia County Medical Society, one of the functions of a hospital is the education of doctors and nurses, and some plan could be profitably adopted whereby the intern could receive more or less systematic instruction, and be actively supervised in his work, which would greatly increase that particular hospital's efficiency as an educator. When we consider that the average intern enters on his duties in a special hospital in the most profound ignorance of the rudiments of his work, the advisability of such a plan would seem to be apparent. Various ways suggest themselves for solving this need. In institutions in which systematic instruction is given, he should be required to attend such instruction, that is, lectures, in the first part of his term. Otherwise the matter could be placed in the hands of a senior intern or house surgeon; or, if only one intern is employed, in the hands of an executive officer or committee or some one specially charged with the work. A little systematic instruction at the beginning will clarify many otherwise confusing subjects, and this instruction can take the form of quizzes, lectures or merely the outlining of a course of study, with such conversations or other interrogations from time to time as will enable the intern to demonstrate that he is preparing himself to take advantage of his opportunipreparing to take advantage of his opportunities.

eases and surgical work will be presented to him sufficiently forcibly; but some special means should be taken to see that he avails himself of the opportunities that are offered to study refraction, ophthalmoscopy and ocular pathology. An intern, like a student, is rarely able to proportion his work wisely, and a little guidance from some one more experienced would enable him to use his time and opportunities to the best advantage. In brief, our present plan gives a man abundant opportunities, but fails in that it does not insure his taking advantage of them.

Incidentally, this inquiry has revealed some interesting facts in regard to the special hospitals in other particulars. You are all aware that the American Medical Association is now conducting an investigation and classification of hospitals, and out of this work will come much good along the line of which I have especially spoken, as well as in other matters pertaining to hospital efficiency. With such plans as those in use at the universities of Minnesota and Michigan, and the systernatic course in ophthalmology given by the University of Colorado, and the graduate courses now being formulated by Harvard University, and the close relation which obtains and which is being further developed between the department of ophthalmology and the department of research medicine at the University of Pennsylvania, both precept and example are at the disposal of those who are charged with these problems of medical education.

\section{CHRONIC NEPHRITIS}

\section{ANALysis OF 250 CASES IN PRIVATE PRACTICE *}

$$
\begin{aligned}
& \text { W. JARVIS BARLOW, M.D. } \\
& \text { AND } \\
& \text { R. L. CUNNINGHAM, M.D. } \\
& \text { LOS ANGELES - }
\end{aligned}
$$

These 250 cases have been tabulated from patients in our private practice occurring over a period of eighteen years. They are considered entirely from the clinical standpoint, and as they represent, in the main, office cases or ambulant patients, they must be regarded as representing Bright's disease of the milde: or earlier type. There is no intention here to enter on the intricate mass of renal pathology, nor have we investigated or tried the several functional kidney tests, which lie beyond the province of this paper; but it is intended to call attention to several groups of nephritic cases observed and treated in Southern California. In making the diagnosis, other factors than the examination of the urine have been considered. It is certain that many patients who show traces of albumin and a few casts do not suffer from nephritis, while true renal disease may occur without albuminuria; but we do recognize that certain persistent findings in the urine, accompanied by changes elsewhere with definite symptoms, are manifestations of a primary or secondary disturbance of the renal function which, when early recognized and given proper treatment, is easily controlled and may become quiescent or arrested.

For the better study of these cases for clinical purposes, an arbitrary classification into four groups has been made (Table 1).

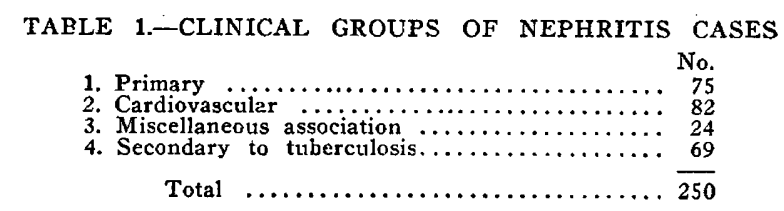

With few exceptions, our cases of true nephritis fall clinically into what is called the chronic interstitial type, in which class they will be discussed. The exceptions include a few that belong to the chronic parenchymatous type and are numbered among those in Group 2, who died; one patient in Group 1 diedacute hemorrhagic. A few others, at first acute or parenchymatous, improved, and naturally fell into the interstitial variety which, we believe, includes most of the degenerative changes that take place in the kidney, whether primary or secondary, as well as the contracted or sclerotic kidney.

\section{EXPLANATION OF CLINICAL GROUPS}

The cases are placed into these groups with reference to their apparent etiology.

Group 1 embraces those which, from their history, followed acute infectious diseases and alcohol, as shown in Table 2.

Group 2 embraces those which accompanied, preceded or followed chronic endocarditis or arteriosclerosis, with or without a history of definite earlier infection.

\footnotetext{
* Read before the Section on Practice of Medicine at the SixtySixth Annual Session of the American Medical Association, San Francisco, June, 1915.
} 